\title{
SOME FACTORS AFFECTING INDICATOR DILUTION CURVES IN THE PRESENCE AND ABSENCE OF VALVULAR INCOMPETENCE
}

\author{
By J. I. E. HOFFMAN * AND GEORGE G. ROWE $\dagger$
}

(From the Department of Medicine, Postgraduate Medical School, Hammersmith Hospital, London, England)

(Submitted for publication June 2, 1958; accepted September 18, 1958)

The indicator dilution technique of Stewart was reintroduced in practicable form by Kinsman, Moore and Hamilton in 1929 (1), was developed further by this group $(2,3)$, and since then has been extensively used to measure cardiac output and central blood volume (the volume of blood between the site of injection and sampling of the indicator). In 1951 Kopelman and Lee (4) observed that tricuspid regurgitation greatly prolonged the time concentration curve, and more recently Korner and Shillingford $(5,6)$ by analysis of data from model experiments attempted to show that the degree of alteration of the curve was proportional to the amount of regurgitant flow.

This principle, that regurgitant flow can be quantitatively or semiquantitatively estimated from indicator dilution curves, has been used recently both for clinical and for physiological studies. Clinically, it has been evaluated as an additional test for estimating the severity of mitral incompetence $(7-10)$; physiologically, it has been used to determine the effects of rest and exercise on tricuspid incompetence (11) and to clarify the role of valvular incompetence in heart failure (12). Underlying all these studies is the assumption that changes in the indicator dilution curve depend only on the cardiac output, central volume and amount of regurgitation. But incompetence of a cardiac valve may be associated with many other hemodynamic changes: The stroke volume and/or heart rate may increase; the distribution of blood volume behind and in front of the incompetent valve may alter; the heart chambers and great veins may change in

* In receipt of a grant from the Medical Research Council. Present address: Department of Cardiology, Children's Hospital, 300 Longwood Avenue, Boston, Mass.

$\dagger$ Markle Scholar in Medicine. Department of Medicine, University of Wisconsin, Madison, Wis. capacity; and distention or disease may alter the elasticity of the atria, ventricles or great vessels and thereby affect streaming and mixing of indicator, particularly in the regurgitant jet. Not all of these changes could be controlled or assessed in the model which Korner and Shillingford used $(5,6)$, and a new model was therefore devised to assess the influence of some of these changes on indicator dilution curves.

\section{MATERIAL AND METHODS}

A rigid model was designed to allow direct measurement of forward and regurgitant flow (Figure 1). In this model the volume upstream (proximal) and downstream (distal) to the valves could be altered by inserting a glass sphere at $S_{1}$ or $S_{2}$; the stroke volume could be changed from 20 to $42 \mathrm{ml}$. by moving the attachment of the piston to the cam; the residual volume of the pump could be changed from 0 to $45 \mathrm{ml}$. by altering the distance between the barrel of the syringe and the cam; and the valve $\mathrm{V}_{3}$ could be made incompetent. When it was incompetent dye dilution curves were made with three types of chamber at $\left.S_{1}: 1\right)$ a $235 \mathrm{ml}$. sphere with its entrance and exit at $90^{\circ}$ to each other $\left.\left(C_{1}\right) ; 2\right)$ a 235 $\mathrm{ml}$. sphere with its entrance and exit at $180^{\circ}$ to each other $\left(C_{2}\right)$; and 3) the $235 \mathrm{ml}$. sphere placed at $S_{2}$ so that the chamber before the pump consisted of the $2 \mathrm{~cm}$. wide tubing of the model $\left(\mathrm{C}_{8}\right)$. During experiments on valvular incompetence the aperture of reflux was constant, and forward and regurgitant flows were regulated by changing the pump rate and the resistances to each outflow. Both forward and backward outflow (at $B_{2}$ and $B_{1}$ ) were collected simultaneously for 30 seconds during the inscription of the dye dilution curve and were measured in the same cylinder to the nearest $5 \mathrm{ml}$.

In some experiments a thin rubber segment dilated to form a distensible chamber $(E)$ of variable size was inserted at $S_{1}$, and valves $V_{1}$ and $V_{2}$ were removed. With each regurgitant jet the elastic chamber dilated and allowed the jet to mix with the incoming water although some of the water in the system was displaced backwards into the reservoir which was open to air. In this elastic system it was no longer possible to measure the regurgitant flow directly, but it could be estimated by subtracting the measured forward output from the total minute out- 
put of the pump. This estimate is approximate because during the downstroke of the piston a small amount of water, found in preliminary experiments with competent valves not to exceed 2 to $4 \mathrm{ml}$. per stroke, flows through the model. As a result the measured forward output is slightly greater than the calculated output of the pump, and the backflow would be underestimated by this method of calculation.

Evans blue dye ( $T-1824)$ was injected rapidly at point I with an insulin syringe fitted with a metal barrel cap to limit withdrawal of the plunger. This syringe could therefore be filled with the same amount each time, and the amount of dye injected (1 mg. per ml.) was found by weighing to be $1.6873 \pm 0.019 \mathrm{mg}$. After each injection the pump was run until all the dye had been washed out of the model and the curve had returned to the base line.

The dye curves were made with a photo cell ear piece oximeter and amplifier (5) and an Evershed direct-writing recorder. As the response was alinear a calibration curve was made from a series of dye solutions of concentration 0.5 to $4.0 \mathrm{mg}$. per $\mathrm{L}$. and the heights of the dye curve at one second intervals were converted by this calibration curve into concentrations in $\mathrm{mg}$. per $\mathrm{L}$. The sensitivity of the system was rechecked after every five to six curves and appropriate corrections were made when necessary.

Five curve parameters and two ratios were studied: 1) slope $(\mathrm{S}) ; 2)$ variance $\left.\left(\mathrm{s}^{2}\right) ; 3\right)$ the time taken for the dye concentration to fall to $0.1 \mathrm{mg}$. per L. (PT) ; 4) appearance time (AT); 5) mean time of the curve (MTT) calculated from the sum of dye concentrations at each second throughout the curve times each corresponding time interval divided by the sum of dye concentration at each second throughout the curve (SCT/ $\mathrm{SC})$; and the ratios PT/AT and PT/MTT.

All outputs referred to are those measured directly, and these were also used in the calculation of central volume. This was calculated according to the methods of Hamilton, Moore, Kinsman and Spurling (3) but modified by fitting the downslope to the first 8 to 10 points of the straight line descent by the method of least squares (13) and by summing the dye concentrations to infinity (14). These modifications were also used in calculating the variance of the curve. Experimental differences between parameters or ratios were evaluated by an analysis of regression technique, the adjusted mean being compared by weighting the variances of the groups (15).

\section{RESULTS $^{1}$}

\section{A. Rigid model, no valvular incompetence}

Dye dilution curves were made with stroke volumes of 20 and $42 \mathrm{ml}$. and residual volumes of 0 and $45 \mathrm{ml}$. To determine how each curve parameter and ratio was related to output and

1 Copies of supplementary tables are available at the Auxiliary Publications Project, Photoduplication Service, Library of Congress, Washington 25, D. C.

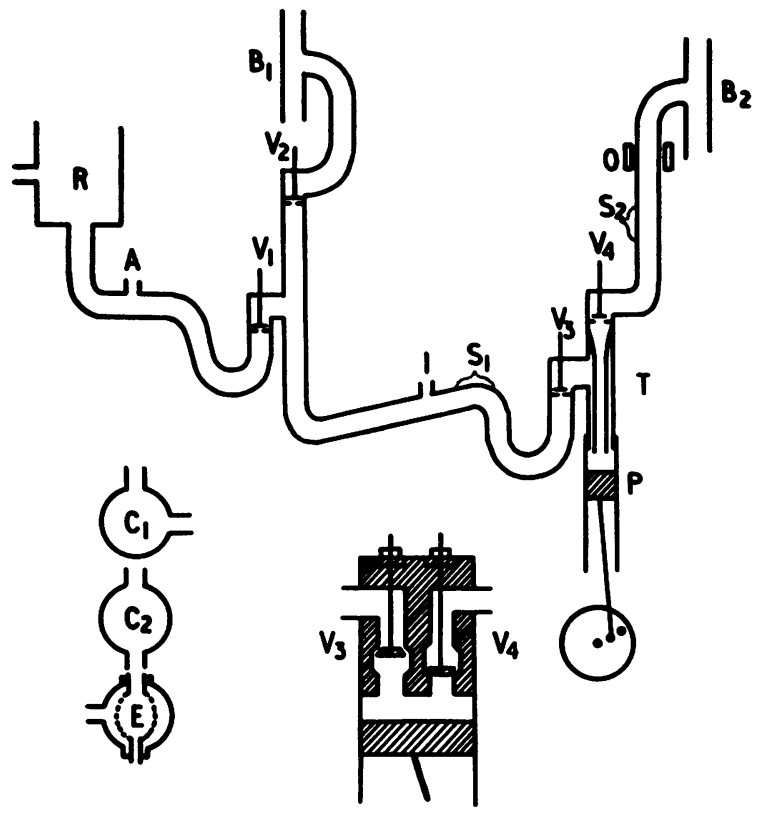

Fig. 1. Diagram of the Model

The diagram is labeled as follows: A, inflow from tap; $B_{1}$ and $B_{2}$, outflow tubes for measuring forward and backward flow, open to air to prevent siphoning; $\mathrm{O}$, oximeter earpiece; I, site of dye injection; $\mathrm{P}$, piston pump (100 ml. syringe). Piston attached to a cam run by a variable speed motor; $R$, reservoir (with spillover to keep head of pressure constant) kept below level of outflow tubes to prevent continuous forward flow; $S_{1}$ and $S_{2}$, sites at which the volume of the apparatus could be altered or an elastic chamber inserted; $C_{1}$ and $C_{2}$, glass spheres inserted at $S_{1}$ and $S_{2} ; E$, elastic segment inside glass sphere inserted at $S_{1} ; V_{1-4}$ gravity valves; and $T$, tube to eliminate dead space.

In some experiments other valves (inset lower center) were substituted for $V_{3}$ and $V_{4}$. When the valves were competent water was pumped out at $\mathrm{B}_{2}$ with little or no spillover (not more than $20 \mathrm{ml}$. per minute) through $\mathrm{V}_{2}$ and out at $\mathrm{B}_{1}$; this small loss was caused by the pressure wave set up each time $V_{3}$ closed and seemed proportional to the force of its closure. When $\mathrm{V}_{3}$ was incompetent, with the rigid model, each regurgitant jet displaced an equal amount of water past $V_{2}$ and out of $B_{1}$; the site of the injection of dye was far enough forward to prevent loss of dye at $B_{1}$, and $B_{1}$ was higher than $B_{2}$ to prevent outflow in the absence of incompetence of $V_{3}$.

central volume the data from each combination of stroke and residual volume were pooled and used to calculate the correlation coefficients and partial correlation coefficients 1 ) between each curve parameter (or ratio) and output and 2) between each curve parameter (or ratio) and central volume. Logarithms of output, central 


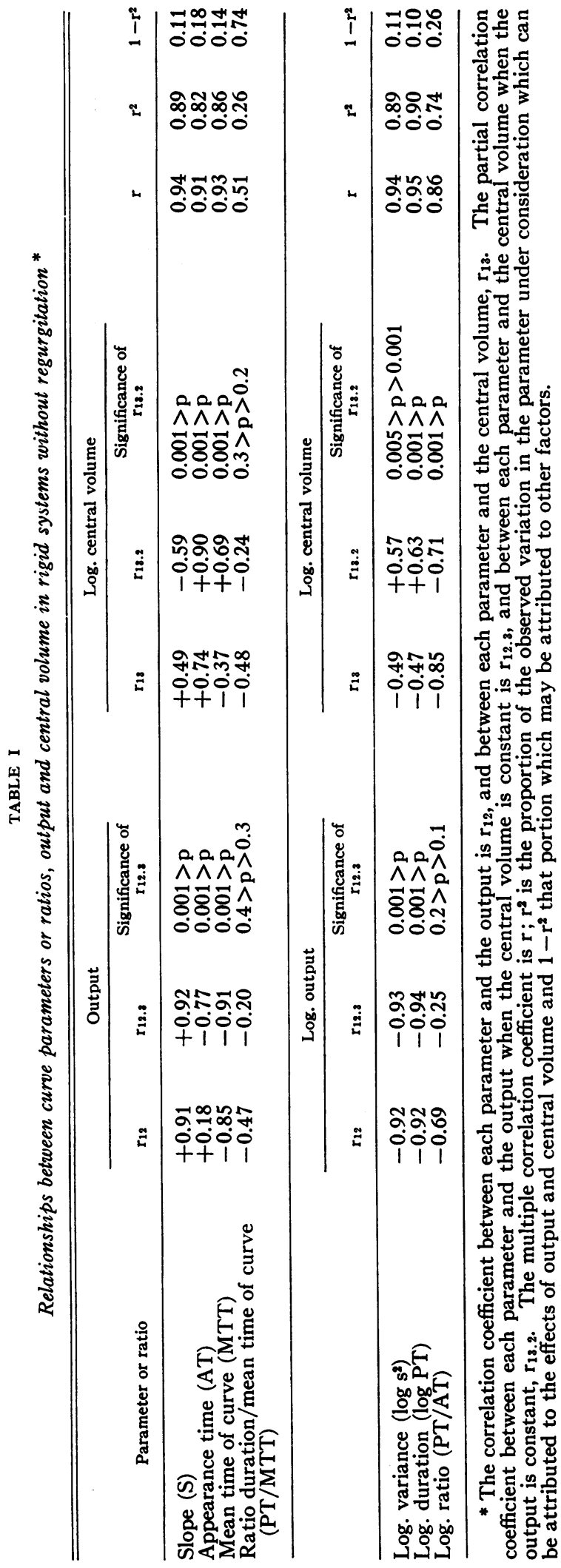

volume or of the parameter or ratios were used if preliminary calculations showed that a higher correlation could be obtained thereby. The multiple correlation coefficient $(r)$ between all three is also given (Table I).

All the curve parameters (but not the ratios) were largely dependent on output and central volume. The small residual variation $\left(1-\mathrm{r}^{2}\right)$ of less than 20 per cent was due to factors other than changes in output and central volume, and included differences resulting from changes in stroke and residual volume as well as from experimental error. Comparisons of the four combinations of stroke and residual volume showed no difference between the slopes of any regression planes except those for the ratio PT/MTT $(0.005>p>0.001)$. The means of each parameter or ratio adjusted to the same output and central volume are given in Table II, as are the relevant variance ratios and estimates of significance. The adjusted mean values in the table were obtained by $a$ ) averaging the forward outputs and central volumes from both groups being compared and then $b$ ) using separate regression formulae for each chamber to adjust the mean value of the parameter or ratio to these averages. In effect this shows what the mean values would have been had all the experiments been made at a constant output and central volume. The values for $\mathrm{C}_{1}$ differ in the two comparisons because the outputs and central volumes used in the experiments with chambers $C_{2}$ and $C_{3}$ were not identical so that the averages they make with the values obtained from the experiments with chamber $\mathrm{C}_{1}$ differ slightly. The adjusted group means showed statistically significant differences for all except slope and variance, although the actual differences were small (e.g., adjusted mean curve times varied from 14.2 to 14.8 seconds) and were not apparent from careful inspection of the individual curves.

\section{B. Rigid model, valvular incompetence}

In all these experiments (the basic data of which is available in supplementary tables) the amount of regurgitant flow and its ratio to the total flow were approximately constant. In each group the forward output varied from 1.5 to 1.9 L. per minute; the backflow varied from 65 to 
TABLE II

Effect of stroke and residual volume in rigid systems without regurgitation. Comparisons of adjusted means*

\begin{tabular}{|c|c|c|c|c|c|c|}
\hline $\begin{array}{l}\text { Stroke volume (ml.) } \ldots \ldots \ldots \ldots \\
\text { Residual volume (mi.) } \ldots \ldots \ldots \ldots\end{array}$ & $\ldots \begin{array}{r}42 \\
\ldots\end{array}$ & $\begin{array}{l}42 \\
45\end{array}$ & $\begin{array}{r}20 \\
0\end{array}$ & $\begin{array}{l}20 \\
45\end{array}$ & $\begin{array}{c}\text { Variance } \\
\text { ratio } \\
\text { F }\end{array}$ & $\begin{array}{l}\text { Estimate of } \\
\text { significance† }\end{array}$ \\
\hline $\begin{array}{l}\text { Slope (S) } \\
\text { Appearance time (AT) } \\
\text { Mean time of curve (MTT) } \\
\text { Duration (PT) } \\
\text { Variance }\left(\mathrm{s}^{2}\right) \\
\text { PT/AT } \\
\text { PT/MTT }\end{array}$ & $\begin{array}{c}0.1011 \\
10.7 \\
14.2 \\
41.5 \\
102.9 \\
3.90 \\
3.05\end{array}$ & $\begin{array}{l}0.1006 \\
9.5 \\
14.8 \\
43.5 \\
108.4 \\
4.59 \\
2.94\end{array}$ & $\begin{array}{c}0.0974 \\
10.1 \\
14.6 \\
42.7 \\
111.4 \\
4.21 \\
3.00\end{array}$ & $\begin{array}{c}0.1008 \\
10.0 \\
14.3 \\
42.6 \\
106.9 \\
4.30 \\
2.98\end{array}$ & $\begin{array}{r}1.68 \\
24.10 \\
5.00 \\
5.27 \\
1.90 \\
13.58 \\
23.37\end{array}$ & $\begin{array}{l}0.3>\mathrm{p}>0.1 \\
0.0005>\mathrm{p} \\
0.025>\mathrm{p}>0.0 \\
0.025>\mathrm{p}>0.0 \\
0.3>\mathrm{p}>0.1 \\
0.0005>\mathrm{p} \\
0.0005>\mathrm{p}\end{array}$ \\
\hline
\end{tabular}

* The means of each of the parameters and ratios were adjusted mathematically to the same output and central volume to allow statistical comparisons between them.

t The estimate of significance gives the probability that all four means came from the same population, i.e., were not affected by changes in stroke and residual volumes. There are small but significant changes in each parameter (and ratio) except slope and variance, and even these showed trends toward change.

80 per cent of the forward output and the central volume ranged from 660 to $736 \mathrm{ml}$. It was therefore possible to determine if the effect of valvular incompetence in changing the curve parameters was dependent on alterations of the chamber proximal to the incompetent valve. Regression equations relating each parameter or ratio to output and central volume were calculated for each type of proximal chamber (sphere with entrance and exit at $90^{\circ}$ to each other $-\mathrm{C}_{1}$; sphere with entrance and exit at $180^{\circ}$ to each other-
$\mathrm{C}_{2}$; tube- $\mathrm{C}_{3}$ ) and statistical comparisons were made between these regression equations from $\mathrm{C}_{1}$ and $C_{2}$ and from $C_{1}$ and $C_{3}$. No differences were shown between the slopes of the regression planes of any of the parameters or ratios except PT/ MTT $(0.05>p>0.03)$ and this only in the comparison of $\mathrm{C}_{1}$ and $\mathrm{C}_{8}$. There were, however, significant differences between the adjusted means of some of the parameters and ratios (Table III).

Curves $\mathrm{A}, \mathrm{B}$ and $\mathrm{C}$ in Figure 2 show dia-

TABLE III

A. Comparison of adjusted means of parameters and ratios from curves made with the rigid model with regurgitant flow obtained for proximal chambers $C_{1}$ and $C_{2}$ *

\begin{tabular}{lcccl}
\hline \multicolumn{1}{c}{ Parameter } & $\mathrm{C}_{2}$ & $\mathrm{C}_{1}$ & $\begin{array}{c}\text { Variance } \\
\text { ratio } \\
\mathrm{F}\end{array}$ & \multicolumn{1}{c}{$\begin{array}{c}\text { Estimate of } \\
\text { significance }\end{array}$} \\
\hline Slope & 0.0820 & 0.0856 & 7.07 & $0.05>\mathrm{p}>0.025$ \\
Appearance time (AT) & 8.4 & 8.5 & 0.02 & $\mathrm{p}>0.5$ \\
Mean time of curve (MTT) & 16.5 & 16.3 & 0.27 & $\mathrm{p}>0.5$ \\
Duration (PT) & 49.0 & 48.0 & 3.05 & $0.3>\mathrm{p}>0.1$ \\
Variance & 155.2 & 143.3 & 7.37 & $0.05>\mathrm{p}>0.025$ \\
PT/AT & 5.86 & 5.74 & 0.47 & $\mathrm{p}>0.5$ \\
PT/MTT & 2.98 & 2.93 & 2.14 & $0.3>\mathrm{p}>0.1$ \\
\hline
\end{tabular}

B. Comparison of adjusted means obtained for proximal chambers $C_{1}$ and $C_{3}$ *

\begin{tabular}{|c|c|c|c|c|}
\hline Parameter & $\mathrm{C}_{1}$ & $\mathrm{C}_{8}$ & $\begin{array}{c}\text { Variance } \\
\text { ratio } \\
\text { F }\end{array}$ & $\begin{array}{l}\text { Estimate of } \\
\text { significance }\end{array}$ \\
\hline $\begin{array}{l}\text { Slope } \\
\text { Appearance time (AT) } \\
\text { Mean time of curve (MTT) } \\
\text { Duration (PT) } \\
\text { Variance } \\
\text { PT/AT } \\
\text { PT/MTT }\end{array}$ & $\begin{array}{c}0.0848 \\
8.6 \\
16.5 \\
48.6 \\
147.6 \\
5.67 \\
2.94\end{array}$ & $\begin{array}{c}0.0922 \\
9.5 \\
15.7 \\
45.4 \\
123.4 \\
4.83 \\
2.93\end{array}$ & $\begin{array}{r}7.91 \\
7.64 \\
6.91 \\
8.92 \\
13.94 \\
7.82 \\
0.06\end{array}$ & $\begin{array}{l}0.05>\mathrm{p}>0.025 \\
0.05>\mathrm{p}>0.025 \\
0.05>\mathrm{p}>0.025 \\
0.025>\mathrm{p}>0.01 \\
0.01>\mathrm{p}>0.005 \\
0.05>\mathrm{p}>0.025 \\
\mathrm{p}>0.5\end{array}$ \\
\hline
\end{tabular}

* The means of each parameter and ratio have been adjusted to the same central volume and output. The central volume and output used in each part of the table is the average for the observations in which the two proximal chambers under consideration were used. This average differs somewhat for $\mathrm{C}_{1}$ vs. $\mathrm{C}_{2}$ as compared with $\mathrm{C}_{1}$ vs. $\mathrm{C}_{3}$ and explains why $C_{1}$ values are not the same in each part of the table. 


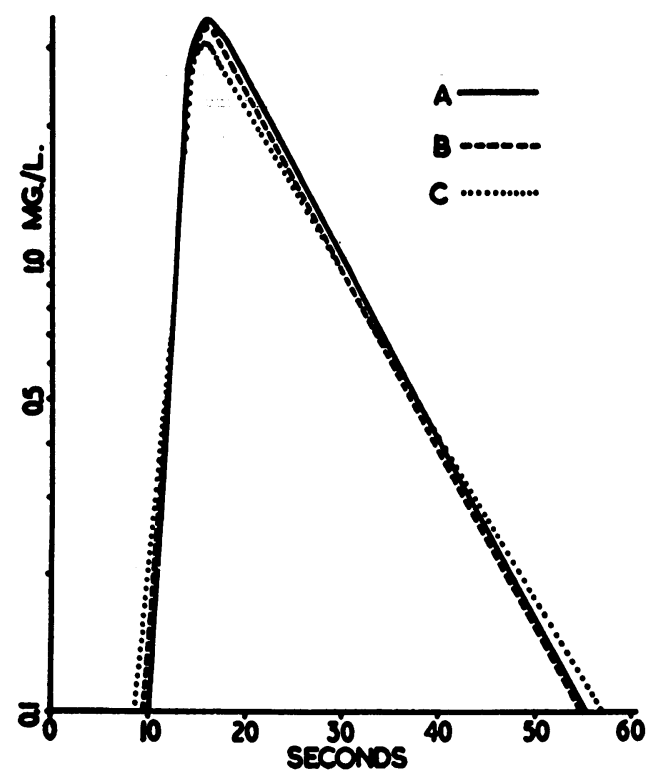

Fig. 2. Composite Diagram to Demonstrate the Difference Produced by Valvular Insufficiency in A RIGID MODEL

For explanation see text.

grammatically the differences between dye dilution curves made when there was no valvular incompetence and those made with proximal chambers $\mathrm{C}_{1}$ and $\mathrm{C}_{8}$ when there was backflow. These composite curves were constructed from separate prediction formulae for each group by adjusting statistically to a constant output of $1.68 \mathrm{~L}$. per minute and central volume of $700 \mathrm{ml}$. the means of the slopes (S), appearance times (AT) and the times taken for the dye concentrations to fall to $0.1 \mathrm{mg}$. per L. (PT). In each composite curve the maximum dye concentration and time at which it occurred is approximate so that the portion of each curve from its appearance to the beginning of the straight line downslope is hypothetical. Curve A was derived from 21 curves made when there was no valvular incompetence, curve $B$ was derived from six curves made with the small proximal chamber $\mathrm{C}_{3}$ when the backflow averaged 75 per cent of the forward flow, and curve $C$ was derived from six curves made with the large proximal chamber $C_{1}$ when the backflow averaged 73 per cent of the forward flow. In all the stroke volume was $42 \mathrm{ml}$.; the residual volume was $0 \mathrm{ml}$. in half the experiments done in each group and $45 \mathrm{ml}$. in the other half.
Valvular incompetence has made the appearance time shorter, the duration of the curve longer, the maximum dye concentration less and the slope smaller. All of these changes were less marked for small proximal chamber $\mathrm{C}_{8}$ (curve $B$ ) than for the large proximal chamber $\mathrm{C}_{1}$ (curve $\mathrm{C}$ ), and despite the relatively large backflows neither composite curve differs greatly from the normal.

The mean circulation time is the sum of the appearance time and the mean time of the curve, both of which may change when there is valvular incompetence. To see if this affected the calculated central volume, analyses were made of dye dilution curves obtained with and without valvular incompetence but with no change in the physical volume of the model. The calculated central volume in these experiments was unchanged by valvular incompetence, but the distortion of the curves was small (Figure 2); it was therefore possible for the shortened appearance time to balance the longer mean time of the curve. With more marked curve distortion this may not occur since the mean time of the curve can be greatly prolonged and it is difficult to see how the appearance time could shorten enough to compensate for this.

\section{Elastic model, valvular incompetence}

Table IV gives the statistics for dye dilution curves made with and without valvular incompetence and with small and large elastic proximal chambers. In all experiments the stroke volume was $42 \mathrm{ml}$. and there was no residual volume in the pump. When the valves were competent the dye dilution curves were similar to, though perhaps slightly less prolonged than, those obtained from the rigid model at similar outputs and central volumes; two few experiments were done with the elastic proximal chamber to test this difference rigorously.

The magnitude of the change in the parameters of the dye dilution curves when valvular incompetence was introduced was related to the size of the proximal elastic chamber. In Experiments $A$ and $B$, illustrated in Figure 3 and marked in Table IV, the forward output and central volume were the same, the regurgitant flow was $2.99 \mathrm{~L}$. per minute in A and $2.40 \mathrm{~L}$. 
INDICATOR DILUTION CURVES IN VALVULAR INCOMPETENCE

TABLE IV

Effect of valvular incompetence and an elastic chamber on dye curves

\begin{tabular}{|c|c|c|c|c|c|c|c|c|c|c|c|}
\hline $\begin{array}{l}\text { Forward } \\
\text { flow }\end{array}$ & $\begin{array}{l}\text { Back- } \\
\text { flow }\end{array}$ & Rate/min. & $\begin{array}{l}\text { Central } \\
\text { volume }\end{array}$ & $\begin{array}{l}\text { Size of } \\
\text { proximal } \\
\text { chamber* }\end{array}$ & Slope & Variance & $\begin{array}{l}\text { Duration } \\
(\mathrm{PT})\end{array}$ & $\begin{array}{l}\text { Appear- } \\
\text { ance } \\
\text { time } \\
\text { (AT) }\end{array}$ & $\begin{array}{l}\text { Mean } \\
\text { time of } \\
\text { curve } \\
\text { (MTT) }\end{array}$ & $\mathrm{PT} / \mathrm{AT}$ & $\mathrm{PT} / \mathrm{MTT}$ \\
\hline $\begin{array}{c}\text { L./min. } \\
2.18 \\
1.56 \\
1.80 \\
1.86 \\
1.58\end{array}$ & L./min. & $\begin{array}{l}52 \\
44 \\
44 \\
44 \\
36\end{array}$ & $\begin{array}{c}m l . \\
748 \\
759 \\
768 \\
786 \\
1,282\end{array}$ & $\begin{array}{l}\text { S } \\
\text { S } \\
\text { S } \\
\text { S } \\
\mathbf{L}\end{array}$ & $\begin{array}{l}0.1425 \\
0.0974 \\
0.1097 \\
0.1167 \\
0.0403\end{array}$ & $\begin{array}{r}52.3 \\
110.1 \\
87.1 \\
77.2 \\
641.5\end{array}$ & $\begin{array}{c}\text { sec. } \\
31.5 \\
46.1 \\
40.0 \\
38.7 \\
88.0\end{array}$ & $\begin{array}{c}\text { sec. } \\
10.0 \\
13.0 \\
12.2 \\
12.0 \\
14.8\end{array}$ & $\begin{array}{c}\text { sec. } \\
10.6 \\
16.3 \\
13.4 \\
13.4 \\
33.9\end{array}$ & $\begin{array}{l}3.15 \\
3.55 \\
3.28 \\
3.23 \\
5.95\end{array}$ & $\begin{array}{l}2.97 \\
2.83 \mathrm{C} \\
2.99 \\
2.89 \\
2.60\end{array}$ \\
\hline $\begin{array}{l}1.55 \\
1.55 \\
1.58\end{array}$ & $\begin{array}{l}2.99 \\
2.40 \\
1.78\end{array}$ & $\begin{array}{r}108 \\
94 \\
80\end{array}$ & $\begin{array}{l}850 \\
847 \\
919\end{array}$ & $\begin{array}{l}\text { S } \\
\mathbf{L} \\
\mathrm{S}\end{array}$ & $\begin{array}{l}0.0903 \\
0.0552 \\
0.0737\end{array}$ & $\begin{array}{l}137.2 \\
334.0 \\
196.9\end{array}$ & $\begin{array}{l}50.4 \\
67.3 \\
58.7\end{array}$ & $\begin{array}{r}14.4 \\
9.9 \\
13.5\end{array}$ & $\begin{array}{l}18.5 \\
22.9 \\
21.4\end{array}$ & $\begin{array}{l}3.50 \\
6.80 \\
4.35\end{array}$ & $\begin{array}{l}2.72 \mathrm{~A} \\
2.94 \mathrm{~B} \\
2.74\end{array}$ \\
\hline
\end{tabular}

* S designates small proximal chamber; L, large proximal chamber (capacity about 400 to $500 \mathrm{ml}$.). Changes in volume of the proximal chamber, with no change in forward output and central volume, have allowed regurgitation to produce gross alterations in curve parameters and ratios. The introduction of an elastic system has made changes, previously detected only by mathematical analysis, obvious.

per minute in $\mathrm{B}$, and the proximal elastic chamber was $235 \mathrm{ml}$. smaller in A than in B. Despite the smaller regurgitant flow in $B$, the alterations of its curve parameters and ratios were much greater than those in $\mathrm{A}$.

\section{DISCUSSION}

It has been recognized since 1932 (3) that the downslope of indicator dilution curves (made without regurgitant flow) was determined largely by output and central volume. This was confirmed by statistical analyses of data obtained from a circulation model and man by Korner and Shillingford $(5,6)$, who also demonstrated that other curve parameters (variance, mean time of the curve) were similarly determined and could be predicted for any output and central volume.

In the present study changes in stroke and residual volume were also shown to have significant effects on the parameters of dye dilution curves. These effects were, however, small (accounting for less than 20 per cent of the total variation, Tables I and II), in spite of the fact that the groups compared ranged from those in which the pump emptied completely or almost completely at each stroke to those in which the residual volume was more than double the stroke volume. These findings do not confirm the theory of Comét and Lagerlöf (16) that the downslope of the indicator-dilution curve is determined by the left ventricular stroke and residual volume and that this relationship can be used to calculate the residual volume of the left ventricle. An exponential washout slope dependent on the ratio $\frac{\text { residual volume }}{\text { stroke + residual volume }}$ would indeed be expected if the indicator were injected into the left ventricle, mixed completely with the left ventricular blood and sampled just above the aortic valve; experimental evidence for this has been presented by Holt (17). If, however, the indicator is injected or sampled far from the ventricle (and it was for this type of curve that Comét and Lagerlöf made their mathematical analysis) the relationships between stroke volume, residual volume and the slope are obscured by the washout slope imposed by the additional

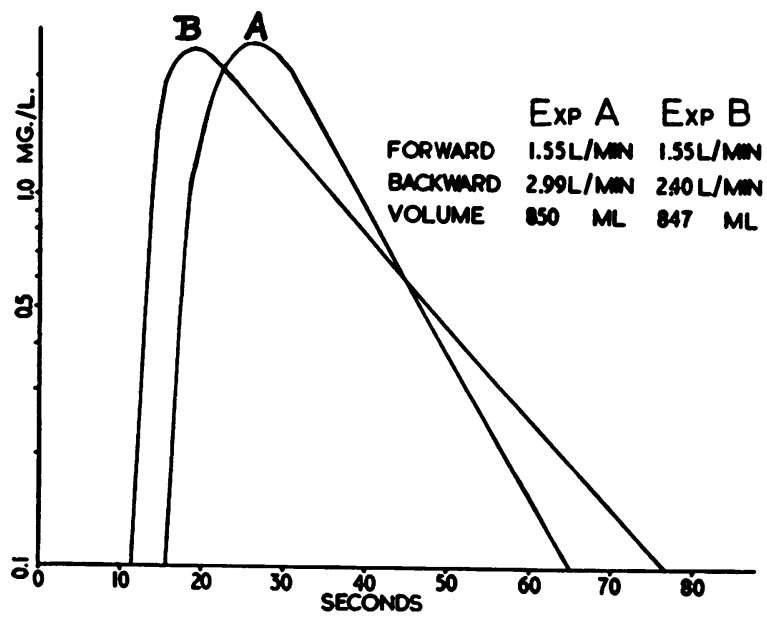

Fig. 3. Dye Curves Made with Small and Large Elastic Proximal Chambers and Valvular IncomPETENCE 
TABLE V

Comparison of backflow observed and estimated by three methods of calculation in the rigid model

\begin{tabular}{|c|c|c|c|c|c|c|}
\hline & \multirow[b]{3}{*}{$\begin{array}{c}\text { Residual } \\
\text { volume }\end{array}$} & \multirow[b]{3}{*}{$\begin{array}{l}\text { Forward } \\
\text { flow }\end{array}$} & \multicolumn{4}{|c|}{ Backflow $(L . / \min .)^{*}$} \\
\hline & & & \multirow[b]{2}{*}{ Observed } & \multicolumn{3}{|c|}{ Calculated } \\
\hline & & & & $\begin{array}{l}\text { Predicted } \\
\text { from slope }\end{array}$ & $\begin{array}{l}\text { Ratio of } \\
\text { variances }\end{array}$ & $\begin{array}{l}\text { Ratio of } \\
\text { slopes }\end{array}$ \\
\hline Tube $\mathrm{C}_{3}$ & $\begin{array}{r}m l . \\
0 \\
0 \\
0 \\
45 \\
45 \\
45\end{array}$ & $\begin{array}{c}\text { L./min. } \\
1.57 \\
1.58 \\
1.80 \\
1.68 \\
1.73 \\
1.78\end{array}$ & $\begin{array}{l}1.24 \\
1.22 \\
1.45 \\
1.30 \\
1.26 \\
1.19\end{array}$ & $\begin{array}{r}-0.06 \\
0.01 \\
-0.05 \\
0.15 \\
0.01 \\
0.13\end{array}$ & $\begin{array}{r}-0.12 \\
0.07 \\
-0.07 \\
0.34 \\
-0.08 \\
0.20\end{array}$ & $\begin{array}{r}-0.07 \\
0.01 \\
-0.06 \\
0.24 \\
0.02 \\
0.17\end{array}$ \\
\hline Sphere $C_{1}$ & $\begin{array}{r}0 \\
0 \\
0 \\
45 \\
45 \\
45\end{array}$ & $\begin{array}{l}1.60 \\
1.66 \\
1.68 \\
1.63 \\
1.66 \\
1.78\end{array}$ & $\begin{array}{l}1.28 \\
1.14 \\
1.20 \\
1.13 \\
1.21 \\
1.11\end{array}$ & $\begin{array}{l}0.08 \\
0.12 \\
0.13 \\
0.17 \\
0.20 \\
0.20\end{array}$ & $\begin{array}{l}0.23 \\
0.36 \\
0.32 \\
0.35 \\
0.44 \\
0.41\end{array}$ & $\begin{array}{l}0.10 \\
0.17 \\
0.16 \\
0.24 \\
0.30 \\
0.27\end{array}$ \\
\hline
\end{tabular}

* Comparison of observed and calculated backflow shows how far off from the actual backflow the calculated amount may be; the amount of error bears little relation to the method used.

central volume. The corollary of this, namely that despite a constant left ventricular stroke and residual volume the downslope changes as the central volume changes, was shown by Hetzel, Swan and Wood (18). They injected dye successively at different sites (pulmonary artery, right atrium, superior vena cava and brachial vein) and found that the curve became lower and wider as the site of injection moved peripherally. Since cardiac output and rate varied little between successive injections and since residual ventricular volume was not likely to have altered much, the changes of slope were therefore related to differences of central volume and independent of stroke and residual volume. Thus, in practice left ventricular stroke and residual volume probably have little effect on the parameters of indicator dilution curves, although if the central volume is small relative to the stroke and residual volume, e.g., with injection into the left atrium or left ventricle, it may not be safe to assume that curve parameters are related only to output and central volume.

With valvular regurgitation varying changes have been found in curve parameters when, with similar amounts of backflow, the type of proximal chamber has been altered; these differences were present even when allowance was made for varia-
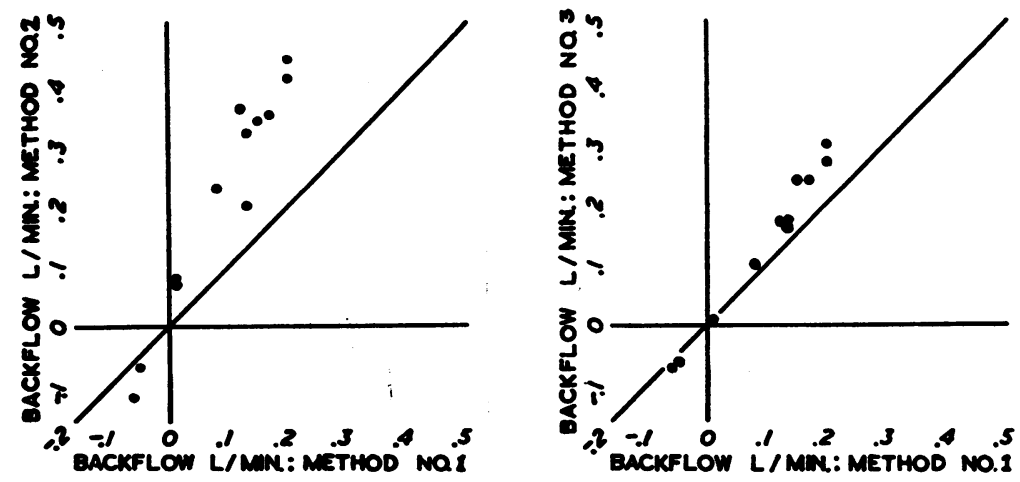

Fig. 4. Comparisons of Backflows Estmated by Different Methods

Method 1: From observed slope reciprocal (5). Method 2: From ratio of predicted to observed variances (6). Method 3: From ratio of predicted to observed slope reciprocals $(8,19)$. 
tion in output and central volume (Tables III and IV). As a result the estimates of backflow by existing methods of calculation $(5,6,8,10)$ varied with the type of proximal chamber, and comparisons between the backflows observed and calculated by three methods are given in Table V. Not only do these estimates differ in rigid systems for the different types of proximal chamber and perhaps for different residual volumes, but they all greatly underestimate the actual backflow. In addition the three methods do not give similar estimates of the same backflow (Figure 4).

In the absence of a sufficiently large series of experiments done without valvular incompetence and with an elastic proximal chamber it was not possible to make a regression equation for predicting curve parameters from output and central volume. It is possible, however, to set limits for these parameters. In Experiment A (Table IV) the upper and lower limits of the slope predicted without backflow are 0.0974 (found in Experiment $\mathrm{C}$ for the same output but a smaller central volume) and 0.0903 (found in Experiment A itself with $2.99 \mathrm{~L}$. per minute backflow); corresponding limits of the predicted curve variance can be determined so that the upper and lower limits of the ratios of predicted and observed slopes and variances can be calculated, and backflows can be estimated $(5,6,8,10)$. The backflow of $2.99 \mathrm{~L}$. per minute in Experiment $A$ is estimated from the ratio of slopes as 0 to $0.12 \mathrm{~L}$. per minute and from the ratio of variances as 0 to $0.38 \mathrm{~L}$. per minute; in Experiment $\mathrm{B}$ the backflow of $2.40 \mathrm{~L}$. per minute is estimated as 0.98 to $1.18 \mathrm{~L}$. per minute from the ratio of the slopes and 2.23 to $3.16 \mathrm{~L}$. per minute from the ratio of the variances. It is important to note that estimates by these two methods differ greatly, that the actual backflow in Experiment A was grossly underestimated by both methods, and that an increase of $235 \mathrm{ml}$. in the proximal elastic chamber has increased the estimated backflow by about $1 \mathrm{~L}$. per minute (slope method) or by about 2 to $3 \mathrm{~L}$. per minute (variance method), even though the actual backflow had decreased. An equivalent increase in the volume of the proximal chamber in the rigid model changed the estimated backflow by about 20 to $40 \mathrm{ml}$. (Table V), a relatively small amount even allowing for the smaller backflow in these experiments.

These observations may best be explained by the hypothesis that most of the changes in the parameters of the curves are due not only to the amount of backflow but also to the dilution of the regurgitated dye. The extent to which dilution occurs may depend upon the volume and shape of the proximal chamber; its elasticity; the force, shape and direction of the regurgitant jet; and swirling and streaming of fluid within the proximal chamber. If the regurgitated dye mixes poorly with the fluid in the proximal chamber, e.g., in the rigid model with the small proximal chamber, it will be little diluted and will rapidly be washed into and out of the pump, so that little distortion of the curve will result. If, on the other hand, the regurgitated dye mixes well with a large volume of fluid in the proximal chamber, e.g., in the model with the large elastic chamber, it will be greatly diluted, its washout will consequently be prolonged and the curve will be greatly distorted. The more the dilution of a given amount of regurgitant dye the lower will be the maximum and mean concentrations of dye at the sampling site. Differences between chambers $C_{1}$ and $C_{2}$ may have been due to streaming, for it has been shown that the positions of the entrance to and exit from a sphere influence the passage of dye through it (19).

This hypothesis has important implications in man, for valvular disease may be associated with great alterations in size, shape and elasticity of the atria and ventricles, and in the force, shape and direction of the regurgitant jet. For example, since the residual volume of blood in the left ventricle in aortic incompetence is probably less than that in the right atrium for an equal amount of tricuspid incompetence, the dilution of regurgitated dye may be less with the aortic lesion and so produce less alteration of the curve parameters. In disease of the mitral valve, too, great variation of left atrial size is well known, calcification of the wall may decrease elasticity and thrombi may influence mixing. Examples of inadequate mixing of dye and blood in the left atrium have been cited by Woodward, Swan and Wood (20). Though it has not been determined how these changes influence curve parameters it is possible 
that they may cause the parameters to vary independently of the amount of backflow and so make difficult its assessment. Finally, in experimental procedures (e.g., rest, exercise, digitalization) it may be difficult to assess not only the amount of backflow but even whether it increases or decreases, for once again the differences produced in the curve parameters may be due to changes in the dilution of the regurgitated dye as well as to its amount.

Parameters and ratios from indicator dilution curves have also been compared with assessments of mitral incompetence made by routine clinical and laboratory methods, and have been found to alter as the severity of mitral incompetence increased $(7,9)$. These methods do not attempt to estimate absolute amounts of backflow, but are necessarily limited in their value by the accuracy of the criteria used to define the severity of the mitral insufficiency and the extent to which the parameters and ratios used are altered by variables other than the amount of regurgitation.

This study has thus shown that several factors other than output, central volume and the amount of backflow may influence the parameters of indicator dilution curves. If the only major variables in a model are forward output, central volume and backflow, it will be possible to construct formulae for relating these to the curve parameters and thus, knowing forward output and central volume, to estimate the amount of backflow. This estimate would not necessarily be correct in different models with additional variables, although if these could be measured it should be possible to construct formulae which take them also into account. It is difficult to be sure that any model successfully reproduces all the variables found in the human, and therefore the extension of formulae derived from any model to calculate the backflow in man should be validated by independent estimates of that backflow in man himself.

\section{SUMMARY}

Dye dilution curves were made in a circulation model in which the amount of forward output and of backward flow through an incompetent valve could be measured directly in a calibrated flask. When the valves were compe- tent, all the curve parameters examined (slope, variance, duration, appearance time and mean time of the curve) were markedly dependent on output and central volume. When the stroke volume of the pump was changed from 20 to 42 $\mathrm{ml}$. and its residual volume from 0 to $45 \mathrm{ml}$. there were slight changes of these parameters as well as of the ratios of the curve duration to 1) the appearance time and 2) the mean time of the curve; these changes were statistically significant for all but slope and variance, and both of these showed trends towards change. It is probable that the changes were small because the central volume was large relative to the stroke and residual volume.

When a valve was incompetent changes were made in the size, shape and elasticity of the proximal chamber entered by the regurgitant jet, and the alterations produced in the curve parameters and ratios by similar amounts of backflow depended in part on these changes. With a narrow and rigid proximal chamber there was little distortion of the curve despite a relatively large backflow, whereas with a large elastic proximal chamber gross distortion of the curve occurred. Although the type of change in the curve was that described by Korner and Shillingford $(5,6)$ (i.e., earlier appearance time, lower and longer curve), backflow estimated in our model by their formulae could differ greatly from the measured backflow and varied with the type of proximal chamber.

The hypothesis is made that the distortion of the indicator dilution curve produced by backflow is due to the dilution and subsequent washout of the regurgitated indicator and that this depends not only on the amount of backflow but also on the nature of the regurgitant jet and the chamber which it enters.

\section{ACKNOWLEDGMENTS}

We wish to express our gratitude to Dr. J. P. Shillingford, in whose laboratory these experiments were done, for use of his equipment and for criticisms and advice during experiments and in the preparation of the manuscript. We would also like to thank Professor J. McMichael for his interest and encouragement, and Mr. N. Please of the University College, London, for advice about the statistical analyses, some of which he adapted specially to suit our problem. 


\section{REFERENCES}

1. Kinsman, J. M., Moore, J. W., and Hamilton, W. F. Studies on the circulation. I. Injection method: Physical and mathematical considerations. Amer. J. Physiol. 1929, 89, 322.

2. Moore, J. W., Kinsman, J. M., Hamilton, W. F., and Spurling, R. G. Studies on the circulation. II. Cardiac output determinations; comparison of the injection method with the direct Fick procedure. Amer. J. Physiol. 1929, 89, 331.

3. Hamilton, W. F., Moore, J. W., Kinsman, J. M., and Spurling, R. G. Studies on the circulation. IV. Further analysis of the injection method, and of changes in hemodynamics under physiological and pathological conditions. Amer. J. Physiol. 1932, 99, 534.

4. Kopelman, H., and Lee, G de J. The intrathoracic blood volume in mitral stenosis and left ventricular failure. Clin. Sci. 1951, 10, 383.

5. Korner, P. I., and Shillingford, J. P. The quantitative estimation of valvular incompetence by dye dilution curves. Clin. Sci. 1955, 14, 553.

6. Korner, P. I., and Shillingford, J. P. Further observations on the estimation of valvular incompetence from indicator dilution curves. Clin. Sci. 1956, 15, 417.

7. Woodward, E., Jr., Burchell, H. B., and Wood, E. H. Dilution curves associated with valvular regurgitation. Proc. Mayo Clin. 1957, 32, 518.

8. Novack, P., Schlant, R. C., Haynes, F. W., and Phinney, A. O., Jr. The hemodynamics of mitral valvular disease (abstract). J. clin. Invest. 1957, 36, 917.

9. Shillingford, J. P., and Zoob, M. Dye dilution curves in the clinical assessment of mitral valve disease. Brit. Heart J. 1957, 19, 589.
10. Novack, P., Schlant, R. C., Phinney, A. O., Jr., Haynes, F. W., and Dexter, L. Korner-Shillingford method for measurement of valvular insuffciency. Fed. Proc. 1957, 16(1), 95.

11. Korner, P., and Shillingford, J. Tricuspid incompetence and right ventricular output in congestive heart failure. Brit. Heart J. 1957, 19, 1.

12. McMichael, J., and Shillingford, J. P. The role of valvular incompetence in heart failure. Brit. med. J. 1957, 1, 537.

13. Snedecor, G. W. Statistical Methods Applied to Experiments in Agriculture and Biology, 4th ed. Ames, Iowa, Collegiate Press, 1946.

14. Hoffman, J. I. E. The calculation of output, central volume and variance from indicator dilution curves. To be published.

15. Kendall, M. G. The Advanced Theory of Statistics, 3rd rev. ed. London, England, Charles Griffin and Co., 1948, p. 244.

16. Comét, S., and Lagerlöf, $H$. A mathematical analysis of indicator dilution curves leading to direct calculation of the systolic and diastolic volumes of the left ventricle and auricle and of the pulmonary blood volume. Acta physiol. scand. 1956, 36, 337.

17. Holt, J. P. Estimation of the residual volume of the ventricle of the dog's heart by two indicator dilution techniques. Circulat. Res. 1956, 4, 187.

18. Hetzel, P. S., Swan, H. J. C., and Wood, E. H. Influence of injection site on arterial dilution curves of T-1824. J. appl. Physiol. 1954, 7, 66.

19. Hoffman, J. I. E., and Shillingford, J. P. Minor factors influencing indicator dilution curves. Clin. Sci. 1957, 16, 1.

20. Woodward, E., Jr., Swan, H. J. C., and Wood, E. H. Evaluation of a method for detection of mitral regurgitation from indicator-dilution curves recorded from the left atrium. Proc. Mayo Clin. 1957, 32, 525 . 